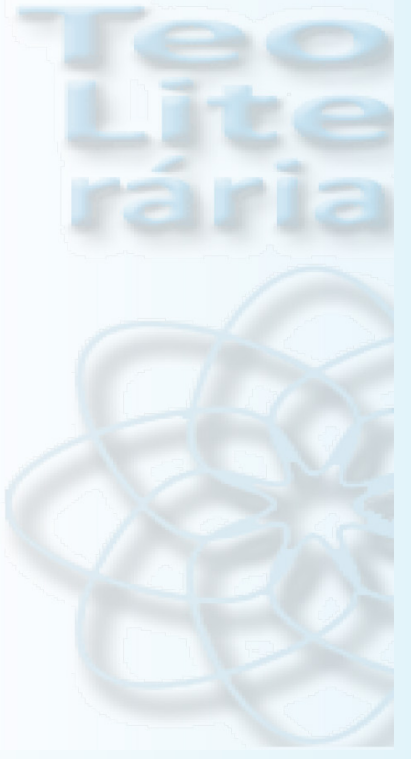

Arquivo enviado em

28/09/2018

e aprovado em

$16 / 03 / 2019$

V. 9 - N. $18-2019$

*Formado em Filosofia e Teologia, pela PUCPR, e também em Letras, pela UEL. Professor de Filosofia,

Mestre em Teologia pela PUCPR, e doutorando em Teologia, também pela PUCPR.

**Doutorado em Teologia pela Pontifícia Universidade

Católica do Rio de Janeiro (2007) com área de concentração em Teologia Bíblica.

Mestrado em Ciências

Bíblicas no Pontifício Instituto Bíblico de Roma (1990). Professor adjunto no Programa de Pósgraduação em Teologia (mestrado e doutorado) da Pontifícia Universidade

Católica do Paraná em Curitiba.

\section{As Teorias de Letramento aplicadas ao ensino bíblico: o estado da questão}

\section{Literacy theory applied to biblical}

teaching: the state of question

$$
\text { João Carlos Domingues dos Santos Rodrigues* }
$$

\section{Vicente Artuso}

\section{Resumo}

Este estudo apresenta, o estado da questão sobre a teoria do letramento aplicada ao ensino bíblico no contexto da Igreja Católica no Brasil. Expõe a origem e princípios da teoria do letramento. Constata no contexto eclesial os desafios de superação de uma leitura parafrástica para uma leitura polissêmica das Escrituras. Grandes passos foram dados com a aplicação de novos métodos e especialmente com o método da leitura popular. A teoria do letramento contribui para uma aproximação mais frutuosa do leitor fiel aos textos sagrados. Apresentadas as preocupações e desafios para superar a leitura fundamentalista o artigo mostra a relação entre leitura popular e teoria do Letramento. Há uma relação de complementariedade no método quando destaca o leitor no seu contexto e intertexto, o que na leitura popular corresponde a ligação da Bíblia com a Vida. Em ambos o leitor é sujeito interpretante.

Palavras-chave: Letramento.

Polissemia. Texto. Leitura. Igreja. 


\section{Abstract}

This study presents the status quaestionis about literacy theory applied to biblical teaching in the context of Catholic Church in Brazil. It exposes the origin and principles of literacy theory and verifies the challenges to the overcome of a paraphrasic reading in ecclesial context towards a polisemic reading of the Bible. Great advances were reached with the application of new methods and especially with the popular reading method. Literacy theory contributes to the reader in order of a more fruitful approaching to sacred texts. After presenting worries and challenges to overcoming a fundamentalist reading, the article shows the relationship between popular reading and literacy theory. There is a complementary relationship on the method when it highlights the reader in his context and intertext, which corresponds in popular reading to connecting the Bible and Life. In both cases, the reader is a interpreting subject.

Keywords: Literacy theory. Polysemy. Text. Reading. Church.

\section{INTRODUÇÃO}

m resposta aos apelos do Concílio Vaticano II, que propôs uma volta as fontes das Escrituras houve um frutuoso diálogo da teologia e os estudos da linguagem em vista de oferecer um acesso mais frutuoso dos fiéis leitores aos textos bíblicos. Em vista disso, a questão que vem se apresentando mais pertinente no ensino das Escrituras, é fazer a passagem de uma leitura 'parafrástica' para uma leitura 'polissêmica' dos textos bíblicos. A questão não está no conteúdo mas no método utilizado no ensino bíblico. Grandes passos foram dados com o método da leitura popular especialmente na Comunidades Eclesiais de Base. Propomos nesse artigo colocar o estado da questão da teoria do letramento aplicado ao ensino da bíblia no contexto da Igreja Católica.

Este método apresenta uma reflexão que já vem sendo feita em outros países há algum tempo. As chamadas "Teorias do letramento" propõem técnicas pedagógicas atuais à formação dos leito- 
res. A partir da Teoria do Letramento, se espera ter critérios mais claros que possam subsidiar o trabalho dos Grupos Bíblicos de Reflexão, de modo a promoverem nos leitores esta passagem de uma leitura literalista (parafrástica) para uma leitura aprofundada e rica (polissêmica) da Bíblia.

No presente artigo, pretende-se apresentar um panorama sobre o estado das pesquisas em torno daquilo que chamamos "Letramento Bíblico". As questões de base para nossa reflexão são: Como a Teologia se posiciona acerca da presença das novas teorias hermenêuticas e pedagógicas? Quais os princípios fundamentais da Teoria do Letramento? Em que consistiriam as possíveis contribuições dessa Teoria para a formação bíblica? Como a academia se posiciona frente a essa aproximação da teoria do letramento aos textos bíblicos?

\section{Desafios católicos}

\section{diante das novas teorias hermenêuticas}

Desde meados do século passado a Igreja Católica vem resgatando o papel da Bíblia na formação cristã dos fiéis, e nesse percurso o Concílio Vaticano II e a Constituição Dogmática Dei Verbum teve importante papel, afirmando com veemência: "É preciso que os fiéis tenham acesso patente à Sagrada Escritura" (DV 21), pois ignorá-las seria ignorar ao próprio Cristo (DV 25).

A partir do Vaticano II, a Igreja Católica assumiu o compromisso de oferecer não apenas o 'Pão Eucarístico' mas também o 'Pão da Palavra' a seus fiéis (DV 21). Por isto a Igreja assumiu o projeto de tornar ainda mais 'consciente', 'ativo' e 'frutuoso' esse contato com a Palavra de Deus (DV 25, SC 11). Além de incentivar o amplo acesso às Sagradas Escrituras, o Vaticano II também 
motivou Bispos e Teólogos a buscarem os meios e técnicas mais adequados para que esse processo ocorresse de modo seguro e útil, gerando um "novo impulso de vida espiritual" em toda a Igreja (DV 25-26; DVe 40; CL 32-35).

Na América Latina, antes mesmo do Concílio, a Igreja buscou empreender essa aproximação mediante o método "Ver-JulgarAgir". Esta iniciativa foi inovadora e de muito sucesso neste objetivo. Porém no Brasil as Comunidades Eclesiais de Base (CEBs) e seus Grupos Bíblicos de Reflexão foram os principais responsáveis por uma nova visão de ser Igreja, traduzida na conhecida expressão de Dom Orlando Brandes, Arcebispo de Aparecida: "Bíblia na mão, no coração e pé na missão!".

Nesse percurso a Igreja forneceu a teólogos, pastores e a todo o povo de Deus, alguns importantes documentos balizadores para essa renovação. Dentre eles destacamos as Constituições Dogmáticas Dei Verbum e Lumen Gentium, a Constituição Apostólica Sacrosanctum Concilium; a Constituição Pastoral Gaudium et Spes; a Exortação Apostólica Verbum Domini e a Exortação Apostólica Evangelii Gaudium. Esses Documentos que pedem: uma ampla difusão das Sagradas Escrituras; uma reformulação das práticas da formação cristã; uma aproximação ativa, plena, consciente e frutuosa das mesas da Palavra e da Eucaristia, por parte dos fiéis; a possibilidade de contribuição das Ciências da Linguagem no estudo das Escrituras. Exortam o povo a uma adesão não apenas racional ao Evangelho, mas existencial que resulte na transformação da vida e das práticas sociais.

No que se refere à interpretação das Sagradas Escritura, importante contribuição foi dada pela Pontifícia Comissão Bíblica, no documento "A Interpretação da Bíblia na Igreja". Este documento reconheceu que as 
Sagradas Escrituras são fonte que alimenta a fé cristã. Porém devido a textos da Escritura serem de uma época antiga e com linguagem e estilo difíceis, se torna imperioso promover uma constante busca por uma meIhor interpretação (PONTIFÍCIA COMISSÃO BÍBLICA, 1993, p. 31-32).

São João Paulo II, no contexto de passagem para o novo milênio, repetia as palavras de Jesus e convidava os cristãos a não ter medo e "avançar para águas mais profundas" (Lc 5,4 - NMI). Impulsionada por tudo isso, a Igreja na América Latina na Conferência de Aparecida, reconheceu a necessidade de dar novos passos em vista de fazer-nos todos mais "discípulos-missionários" de Jesus. Esta iniciativa foi patrocinada pelo Papa Bento XVI e difundida a toda a Igreja pelo Papa Francisco. Os Bispos do Brasil querendo promover a "conversão pastoral da paróquia" constataram que "muitos paroquianos ainda não se familiarizaram com a Bíblia" (Doc 110, 271). Tal constatação indica haver problemas no processo de Letramento Bíblico e, por consequência, de edificação da Comunidade Eclesial por meio da Palavra.

\section{Teoria do letramento: origem e princípios}

O conceito 'letramento' surge no Brasil nos anos $80^{1}$, com os estudos de Educação e Ciências da Linguagem especialmente com a obra de Mary Kato em 1986: "No mundo da escrita: uma perspectiva psicolinguística". Esta obra na época não deixava claro a compreensão de 'letramento. O conceito de letramento foi melhor definido com Angela Kleiman, em seu livro "Os significados do letramento".

O que significaria então ser "letrado"? O indivíduo letrado é

1. A partir desta data e da afirmação da importância da disciplina de Linguística Aplicada diversos são os estudos que vem sendo realizados em importantes Universidades do país,como: Unicamp (Universidade Estadual de Campinas); USP (Universidade de São Paulo); UFMG (Universidade Federal de Minas), PUCSP (Pontifícia Universidade Católica de São Paulo); UFSM (Universidade Federal Santa Maria - RS) e UCS (Universidade de Caxias do Sul - RS). 
o que atua de modo competente no uso social da língua, compreendendo e produzindo textos dos mais diversos gêneros e temas. Letrado é aquele capaz de ler o texto em suas entrelinhas, selecionar os recursos linguísticos apropriados a seus objetivos e à circunstância em que o discurso será realizado. Portanto letrado é distingo do alfabetizado, aquele que sabe ler e escrever. $\mathrm{O}$ letramento é um processo que se inicia muito antes do indivíduo saber ler, saber decodificar os signos linguísticos. O processo de letramento está ligado à compreensão do lugar que esse indivíduo ocupa no mundo e o modo como ele se apropria da própria cultura e da linguagem. Décadas antes, Paulo Freire destacava a ligação entre linguagem e seu contexto como inseparáveis:

A leitura do mundo precede a leitura da palavra, daí que
a posterior leitura desta não possa prescindir da conti-
nuidade da leitura daquele. Linguagem e realidade se
prendem dinamicamente. A compreensão do texto a ser
alcançada por sua leitura crítica implica a percepção
das relações entre o texto e o contexto (1992, p. 11-12).

Promover o letramento não seria propriamente ensinar, mas promover que o indivíduo seja capaz de transpor todo seu conhecimento prévio para o mundo das letras, do qual se mantinha distante.

Segundo Magda Soares (2009) o conceito 'letramento' tem sua origem no termo em inglês 'literacy', que nesta língua significa a "condição de ser letrado", sendo compreendido lá como sinônimo de 'alfabetização'. Pode se dizer que as dificuldades quanto à conceituação de 'letramento' devem-se ao fato de ele cobrir "uma vasta gama de conhecimentos, habilidades, capacidades, valores, usos e funções sociais" (SOARES, 2009, p. 65). Quando, então, utilizamos este conceito temos em mente um fenômeno mais am- 
plo que aquele dos domínios da escola, o definindo como "um conjunto de práticas sociais que usam a escrita, como sistema simbólico e como tecnologia, em contextos específicos, para objetivos específicos" (KLEIMAN, 2008, p.18). Assim, se tornaria 'letrado' o indivíduo ou grupo social que utiliza das habilidades linguísticas agindo na sociedade por meio da linguagem.

a) Mikail Bakhtin, com sua Teoria da Enunciação, está na origem da concepção de letramento. Ele apresenta uma perspectiva do uso da língua ao valorizar o enunciatário e os conhecimentos que este traz consigo no momento da interação com o enunciado. Nessa esteira, Kleiman afirmará que o fenômeno do letramento "extrapola o mundo da escrita" (2008, p.18). Com efeito o letramento envolve um conjunto de práticas sociais com objetivos e em contextos específicos que estão para além da mera decodificação de informações. Esse fenômeno requer uso de múltiplas fontes de conhecimento para que possa haver efetiva compreensão e frutuoso diálogo com o enunciado (2008, p.151).

b) A elaboração didática de um conhecimento que leve em conta o conceito de 'letramento' e seus princípios estrutura-se a partir de quatro eixos: $1^{\circ}$ ) O currículo/ conteúdo deve ser dinâmico e dialogar com os vários conhecimentos que os indivíduos já trazem consigo. $2^{\circ}$ ) O currículo/conteúdo deve partir da realidade local, fazendo as atividades úteis ao indivíduo. $3^{\circ}$ ) A prática social e não o currículo/conteúdo é o foco principal, pois o mais importante é que o indivíduo seja capaz de dialogar com tais conhecimentos e por meio deles significar sua vida cotidiana. $4^{\circ}$ ) O currículo/conteúdo tem a função de orientar todo o processo, já que o objetivo é contribuir para que o indivíduo seja capaz de estabelecer conexões entre seus conhecimentos.

Tais eixos são compreendidos a partir de duas dimensões básicas: Dimensão Individual: Levar o indivíduo à autonomia e ao pleno uso de suas habilidades linguísticas. Dimensão Social: Promover a transformação das realidades à medida que se amplia a compreensão dos indivíduos. 
Tendo claros os princípios orientativos da teoria do letramento, passemos aos conceitos envolvidos no processo de leitura: autor e leitor. Esses conceitos, tanto autor quanto leitor, destacam-se por serem historicamente e ideologicamente localizados. Entretanto, o indivíduo (seja como autor ou como leitor) atua subjetivamente dentro de seus condicionamentos, não se limitando a eles (PINSKY, 2011, p.19). Assim, ao falar sobre o autor Bakhtin afirma que ele "está por inteiro no produto criado" mas "apenas nela (na obra) é que devemos procurá-lo" (1997, p.28), pois "vemos o criador apenas em sua criação, jamais fora desta criação” (1997, p.403). Daí surge uma distinção entre o "autor-criador" e o "homem-autor", sendo que o "homem-autor" é o indivíduo biográfico; já o "autor-criador" é o sujeito do discurso, o posicionamento assumido pelo indivíduo biográfico, inserido numa determinada formação discursiva. O primeiro é componente da vida, o segundo componente da obra (BAKHTIN, 1997, p.32).

O leitor, marcado por seus condicionamentos ideológicos, age de modo responsivo-ativo ao entrar em contato com a obra. Esse leitor concorda ou discorda (total ou parcialmente) do texto, o completa e/ou adapta, em um constante processo de colaboração com o autor. (BAKHTIN, 1997, p.291). A enunciação surge da interação entre o leitor e texto, podendo ser distinta para distintos leitores.

A aproximação entre autor e leitor se dá por meio do texto (da obra), caracterizado como produto da atividade da linguagem em permanente funcionamento na sociedade (BRONCKART, 2009, p.137). Como produto da atividade da linguagem, o texto pode ser compreendido sob duas dimensões: Uma primeira mais tradicional, ligada à escrita e a representação gráfica das palavras; e outra dimensão mais ampla, que entende por texto toda a manei- 
ra de configurar signos, seja de forma verbal ou não verbal. Esta perspectiva mais ampla é a que possibilita ver como textos também pinturas, esculturas, músicas, danças e gestos. Entretanto, por mais diversas que possam ser as plataformas de produção e divulgação de um texto, e por mais numerosos que possam ser os gêneros textuais, existem apenas dois tipos de discursos capazes de manifestar todos os processos de semiotização dessa atividade da linguagem. Conforme Bronckart, esses discursos são chamados de "arquétipos psicológicos". São eles, os da ordem de narrar um tipo representação que faz referência a fatos passados e confirmados, a fatos futuros, e os da ordem do comentar (expor) Nesse caso o mundo discursivo se situa "em outro lugar". Se organiza em referência mais ou menos direta ao mundo da ação da linguagem, sendo interpretado à luz dos critérios de validade do "mundo ordinário" (BRONCKART, 2009, p.153).

Tanto leitor quanto autor e texto são entidades históricas e geográficas. Portanto, estão inseridos em um contexto. O contexto, segundo as professoras Lesley Rex, Judith Green e Carol Dixon, é uma entidade tão complexa quanto o leitor, o autor e o texto, não devendo ser reduzido a meros dados históricos ou geográficos. Ele pode ser agrupado em três dimensões: O contexto "com-o-texto", que é aquele contexto da formação discursiva do texto, das características do evento de letramento no qual ele se insere, devendo ser processadas pelo leitor. O contexto "ao-redor-do-texto", que se refere aos elementos exteriores ao texto, mas que influenciam diretamente na elaboração do sentido deste. Nesse caso, o contexto abarca as esferas sociais e culturais mais imediatos nas quais 0 texto e o leitor se inserem. O contexto "além-do-texto", engloba as dimensões mais amplas da sociedade, da cultura e da história, 
atuando indiretamente sobre o texto e o leitor (1998, p.414).

Não menos importante é o intertexto, que diz respeito às relações textuais de diálogo e polifonia presentes nos discursos contidos nos textos. O reconhecimento da presença dos intertextos possibilita a ampliação do potencial discursivo de um dado texto. Trata-se pois, de um elemento fundamentalmente reflexivo no ato da leitura. Há uma tríplice articulação nos núcleos de sentido presentes no intertexto: O primeiro diz respeito ao fato de que todo texto está ancorado numa formação discursiva específica que é anterior ao próprio texto e do qual este se nutre, tal como a estrutura do gênero utilizada; o segundo núcleo é o da trama interna do texto, ao modo como este é coerentemente e coesamente construído; já o terceiro se encontra na relação entre leitor e texto, alimentado a partir de outros textos que o leitor traz presente no ato da leitura e à finalidade com a qual ele leitor se aproxima de um dado texto (COSSON, 2014, p.61).

Segundo Rildo Cosson (2014, p.37-41) esses importantes conceitos fazem parte dos elementos que articulam a leitura. Ele chama atenção ao fato de que dependendo da ênfase dada por determinadas teorias à figura do autor, do texto, do leitor ou do contexto, no processo de leitura, será possível identificar quatro perspectivas distintas de leitura: $1^{\mathrm{a}}$ ) A perspectiva chamada 'tradicional' á aquela centrada no 'autor'. Segundo essa perspectiva, ler é o ato de emprestar nossa atenção ao autor e ouvir o que este tem ou quis nos dizer. Ler se torna o ato de buscar o sentido da intenção do autor. $2^{\mathrm{a}}$ ) A perspectiva centrada no 'texto'. Nesse caso, a leitura tem no texto o seu limite, e somente aquilo que objetivamente pode ser observado no texto é digno de atenção. Ler se torna o ato de decifrar o texto e decodificar as informações 
nas várias camadas das quais ele é composto (estilística, retórica e etc.). $3^{a}$ ) A perspectiva centrada no 'leitor'. Aqui o foco está na interação entre o leitor e o texto, sendo que o sentido do texto é construído no momento em que se efetiva essa interação. Ler é visto como ato de construir o sentido do texto, pois, o sentido sem o leitor é apenas um reservatório de palavras. $4^{a}$ ) Nas últimas décadas vem ganhando espaço uma perspectiva centrado no 'contexto'. Segundo essa perspectiva a leitura é sempre leitura de algo, com alguém e para alguém, pois a comunidade, o coletivo, a sociedade, a cultura, agem sempre como instâncias reguladoras da leitura. Deste modo, ler se torna sempre uma atividade social de uma comunidade discursiva.

Independente do destaque que se dê, o ato de ler (a leitura) será sempre um processo que abarca as esferas do autor, texto, leitor e contexto (COSSON, 2014, p.41). A perspectiva de leitura que se pretende apresentar buscará conjugar essas quatro esferas, com ênfase no leitor, no contexto e no modo como cada uma se aproxima das três realidades do texto (os três objetos da leitura).

Tendo apresentado as esferas, os componentes que envolvem o processo de leitura, tratemos de compreender o objeto desse processo. Nildo Cosson (2015, p.72-80) destaca no ato de ler a mediação de três objetos (realidades): o 'texto' em si, o 'contexto' do texto e os 'intertextos' do texto. A ênfase que é dada no modo de se aproximar de cada uma dessas realidades, por cada uma das quatro esferas da leitura já apresentadas, dará acesso a distintas dimensões, distintas leituras, sendo elas:

1a) Quando o objeto da leitura é o contexto: a) contexto-autor= Busca relacionar a obra com a vida do autor, fortemente ligada a dados biográficos e como este viveu sua cultura. b) contexto- 
-leitor= Traça paralelos entre a obra e o leitor, o emocionando ou reafirmando convicções. c) contexto-texto $=$ É aquela que procura no texto o que é dado no contexto, como o texto manifesta seu próprio contexto. d) contexto-intertexto= A obra se torna um meio para discutir questões da sociedade ou de um saber específico.

2a) Quando o objeto da leitura é o texto: a) texto-autor= Voltada para o estilo do autor e suas marcas identitárias de escrita, mostrando sua singularidade na escrita ou sua evolução. b) texto-leitor= Centrada na trama, nas imagens sensoriais e efeitos sobre o leitor, no mundo virtual do texto. c) texto-contexto= Analisa a materialidade da obra, o como foi produzida (o paratexto), o modo de veiculação, e como isso afeta o sentido da obra. d) texto-intertexto $=$ Voltada para a linguagem empregada na obra, os recursos estilísticos e demais detalhes de sua elaboração, bem como da relação do texto com outros textos afins.

3a) Quando o objeto da leitura é o intertexto: a) intertexto-autor= Demonstrando como o autor dialoga, por seu obra, com outro conjunto de textos, reforçando ideias ou as questionando. b) intertexto-texto $=$ Volta à percepção das referências a outros textos na tessitura daquele texto específico (paródia, paráfrase, estilização, pastiche, alusão, citação, écfrase e ilustração), ampliando ou revendo os sentidos da obra. c) intertexto-leitor= Aproximação do texto lido a outros textos lidos pelo leitor. Promove o diálogo de obras aparentemente distantes. d) intertexto-contexto= Identifica como os arranjos dos gêneros e/ou estilos (as marcas abstratas) se fazem presentes naquela obra específica (produção concreta), criando um diálogo entre gênero e/ou estilo e sentido na obra.

Observa-se que para cada realidade que compreende o texto (cada objeto: texto, contexto, intertexto) é possível promover a 
aproximação sob cada uma das quatro esferas da leitura, gerando uma ampla possibilidade de Métodos que concretizem o processo de Letramento. Dentre essas diversas possibilidades a que mais nos chama atenção é aquela que mantém seu foco junto à realidade do intertexto e seus três núcleos de sentido.

A escolha de manter o foco da atividade de leitura no intertexto coaduna-se perfeitamente ao método que os evangelhos relatam ter sido utilizado por Jesus para apresentar sua mensagem a seus contemporâneos; bem como ao método utilizado pelos primeiros pais da fé. Eles atualizam e oferecem um significado para seus ouvintes e leitores. Capaz de levar a uma mudança na prática. Assim mediante o letramento o leitor será apto a uma leitura mais competente e rica do ponto de vista linguístico, teológico, e espiritual.

\section{A academia frente à aproximação: teoria do letramento e reflexão bíblica}

Em vista de avaliarmos como a academia se posiciona sobre a aproximação das Teorias do Letramento e o estudo da Bíblia, pesquisamos, em plataformas acadêmicas, a partir das seguintes palavras-chave: letramento; alfabetização; letramento bíblico; alfabetização bíblica; letramento religioso; literacy e biblical literacy; alfabetización bíblica; alfabetizzazione bíblica e alphabétisation biblique. Em nossas pesquisas, recorremos tanto à palavra 'letramento' quanto 'alfabetização.

Um dos primeiros lugares a que nos dirigimos para o levantamento acerca das pesquisas em torno de nosso tema foi o 'Repositório da produção científica e intelectual da Unicamp'2. Nessa instituição aturam as professoras Mary Aizawa Kato e

2. Segue o link: http://repositorio.unicamp.br 
Angela Bustos Kleiman, responsáveis pelos primeiros estudos e pesquisas sobre a temática do letramento no Brasil. Observamos que produções acerca do tema 'Letramento' ganharam destaque nas últimas duas décadas. Os estudos versaram desde as perspectivas pedagógicas na formação de jovens e adultos até o diálogo com o hip-hop e os jogos de vídeo-game. Todavia, apenas um trabalho, em mais de 140 teses e dissertações, versava sobre a temática letramento e religião. Trata-se da tese doutoral de Elaine Botelho Corte Fernandes, intitulada: "Aqui é o lugar do surdo. $\mathrm{E}$ põe essa imagem mais pra lá': línguas, representações e territórios em práticas de letramento de uma comunidade surda em contexto religioso ouvinte". O enfoque da tese foi o ensino da Língua Brasileira de Sinais (LIBRAS) e a religião, e o espaço religioso, como espaço privilegiado para esse tipo de letramento.

Junto ao Banco de Teses e Dissertações da PUCSP ${ }^{3}$, instituição na qual já trabalhou a professora Mary Kato, foi possível observar um amplo leque de estudos acerca do letramento. Porém, ali apenas um trabalho se aproximou de nossa temática: a dissertação de Fabio Fetz de Almeida, intitulada: "A leitura e a escrita como prática religiosa: um estudo de caso sobre crianças e adultos pertencentes à Igreja Metodista". Este autor buscou compreender como as atividades da escola dominical da Igreja Metodista contribuíram nas práticas de leitura e escrita de crianças e adultos.

Junto ao Banco de Teses e Dissertações da UFMG ${ }^{4}$, Universidade na qual atua a professora Magda Becker Soares, outra importante teórica e pesquisadora do letramento no Brasil, não foi possível encontrada nenhuma tese ou dissertação que propu-

3. Segue o link: https://sapientia.pucsp.br/

4. Segue o site: http://www.bibliotecadigital.ufmg.br 
sesse uma aproximação entre letramento e religião ou letramento e a Bíblia.

Num levantamento mais abrangente, junto ao Catálogo de Teses e Dissertações da Capes $^{5}$, das 3721 teses e dissertações sobre o tema 'letramento'6, as 5 instituições com maior número de pesquisas foram justamente a Unicamp, a UFMG, a PUCSP, a $U_{S P}^{7}$ e a UnB ${ }^{8}$. Também desse rol de produções apenas outras duas surgiram no catálogo, mas também elas não tratavam diretamente sobre a temática por nós pesquisada - refiro-me à dissertação de Ana Paula Campos, sob o título: "Minha caneta é a enxada: Um Estudo sobre Letramentos na Comunidade Quilombola do Taquaral em Três Corações". Ela tratou do letramento em uma comunidade quilombola e a contribuição da religião nesse processo; bem como à tese de Maria Nívia Dantas, intitulada: "Mundos de letramento e agência na formação da identidade do seminarista", que focou no papel de instituições como o seminário no letramento e formação identitária dos seminaristas.

Mesmo em importantes centros de Teologia no Brasil (como FAJE $^{9}$ e a Universidade Metodista de São Paulo) não encontramos referências a produções científicas que versassem sobre a temática do letramento bíblico ou mesmo de letramento religioso. Por sua vez, pudemos encontrar uma publicação na Revista

5. Segue o site: http://catalogodeteses.capes.gov.br/catalogo-teses/\#!

6. O rol de teses presente no catálogo da CAPES abarca os últimos 26 anos, sendo que é do ano de 2002 em diante que há um maior interesse dos pesquisadores sobre o tema do letramento.

7. USP = Universidade de São Paulo.

8. UnB = Universidade de Brasília.

9. FAJE= Faculdade Jesuíta. Segue o site: http://www.faculdadejesuita.faje.edu.br/dissertacoes-teologia-437 
Jesus Histórico ${ }^{10}$, da UFRJ11, intitulada: "'Quem vos ouve, ouve a mim': tradições orais na transição do Jesus histórico ao cristianismo mais primitivo"12, que embora não tratando diretamente sobre nosso tema, apresenta uma discussão acerca de como os níveis de letramento influenciaram tanto na redação quanto na recepção dos evangelhos por parte dos primeiros cristãos. Tal reflexão vem ao encontro de nosso objetivo pois esses autores demonstram como a figura de Jesus e de sua mensagem foi marcada pelos níveis de letramento das primeiras comunidades na transposição da tradição oral para a tradição escrita. O mais importante, é o fato desses autores se preocuparem em construir 'zonas de desenvolvimento proximal' facilitando o processo de compreensão e adesão da fé cristã.

Ao buscarmos referências a 'alfabetização bíblica' pudemos comprovar a inadequação desta terminologia à nossa pesquisa, mesmo sabendo que em inglês o termo literacy, do qual deriva a palavra letramento, possa também ser traduzido por 'alfabetização'. Todas as indicações de sites, artigos ou livros que continham o termo 'alfabetização bíblica' ou faziam referência a uma aprendizagem sobre como a Bíblia está organizada, número de seus livros, seus autores e como encontrar um citação. Outros estudos tomavam por objetivo uma espécie de instrução acerca de uma "verdadeira" interpretação dos textos bíblicos a que o leitor ou praticante dos "passos indicados" teria acesso ao final do percurso.

Com a pesquisa do termo "alfabetización biblica" foi possível

10. A Revista Jesus Histórico tem por interesse editorial, trabalhos com enfoque nas recentes pesquisas sobre o campo das experiências religiosas. Classificada no quadriênio 2013-2016 como B3.Segue o link da revista: http://www.revistajesushistorico.ifcs.ufrj.br 11. UFRJ = Universidade Federal do Rio de Janeiro.

12. O artigo é da autoria de Lair Amaro dos Santos Faria. Disponível em: http://www. revistajesushistorico.ifcs.ufrj.br/arquivos6/Artigo\%20Lair\%20Ribeiro.pdf 
identificar muitos sites e textos científicos que o compreendem ainda no nível parafrástico da leitura. As dicas, orientações e mesmo aulas em vista de um letramento bíblico (alfabetización biblica) apresentavam a preocupação de meramente levar o leitor (o fiel) a ter mais contato com os textos, saber identificar os textos e suas referências na própria bíblia; quando muito, se aproximavam de técnicas de leitura orante. Tal enfoque parafrástico de aproximação da Bíblia pode ser observado nas orientações dadas no site Sociedades Bíblicas Unidas ${ }^{13}$ acerca do analfabetismo bíblico, numa perspectiva diametralmente oposta àquele que buscamos apresentar, especialmente quando trata aquele os ditos "analfabetos bíblicos" como desprovidos de capacidades individuais para aprender e compreender a Bíblia:

¿Qué es el analfabetismo bíblico? Se podría definir como creyentes que, si bien tienen una Biblia al alcance de la mano, y escuchan predicaciones en la iglesia, carecen de la capacidad individual de aprender, entender y profundizar por sí mismos los principios revelados en la Palabra de Dios. Ellos carecen del deseo e interés propio para leer, meditar y estudiar en las Sagradas Escrituras lo cual los conduce a ser unos ignorantes espirituales (2018).

Quando, por sua vez, nossa busca focalizou o conceito "alfabetizzazione bíblica", além da compreensão superficial de caráter mimético e mnemônico quanto à instrução bíblica, também pudemos encontrar uma perspectiva que se assemelha bastante àquela que se pretende por um letramento bíblico. Um exemplo disso encontramos no artigo “L'alfabetizzazione della Bibbia”, de Domenico

13. As Sociedades Bíblicas Unidas (SBU), fundada em 1946, reúnem 147 Sociedades Bíblicas, atuando em mais de 200 países. Essas entidades são orientadas pela missão de promover a maior distribuição possível de Bíblias, numa linguagem que as pessoas possam compreender e a um preço que possam pagar. A Sociedade Bíblica do Brasil (SBB) é membro da SBU. 
Maselli. Esse autor faz um levantamento histórico das diversas estratégias utilizadas para aproximar a Bíblia dos leitores, indo desde a transmissão por alegorias e pela homilia (na Patrística), passando pelas manifestações culturais (como a "Divina Comédia" de Dante Alighieri), até o contato físico com o texto (em nossos dias). Em todos esses momentos é destacado o como essas iniciativas se valiam do contexto da época e do contexto das pessoas para proporcionar uma eficaz "alfabetização bíblica". O autor faz uma afirmação bem enfática sobre a forma de abordagem dos textos em vista da verdadeira alfabetização bíblica, ou letramento bíblico:

La vera alfabetizzazione biblica avverrà quando affronteremo laicamente e scientificamente i nodi culturali che la Bibbia ancora mantiene per noi, quando la leggeremo in dialogo con i testi delle altre religioni universali, quando saremo in grado di farne il collante del nostro modo di pensare, come fece, in altri tempi [...] (MASELLI, 2018).

A obra "Adulti nella comunità Cristiana: Guida alla preparazione di itinerari per l'evangelizzazione, la crescita nella fede e la mistagogia della vita Cristiana", de Mariella Barghilioni, Egidio Barghilioni e Luciano Meddi, voltada à Catequese de Adultos, no itinerário proposto pelos autores há um destaque para as habilidades de ler e interpretar as Escrituras e de ler a vida através das Escrituras. Isso é possível não mediante qualquer leitura, mas mediante uma leitura atualizante que saiba identificar os "segni dei tempi" (2008, p.99). Tais habilidades de leitura estão consonância com os objetivos um letramento bíblico eficaz. Para que a haja a "alfabetizzazione bíblica" a obra aponta a necessidade de "appropriati strumenti di lettura e di comprensione" (BARGHILIONI; BARGHILIONI; MEDDI, 2008, p.99).

Bastante comum no meio Protestante e Evangélico é o conceito "alphabétisation biblique". Na grande maioria dos sites, revistas e livros pesquisados, a alfabetização prevalece ligada a uma 
instrução. Um exemplo da utilização do conceito 'alfabetização bíblica' de modo superficial é aquele presente na revista trimestral da Sociedade Bíblica Suíça, La Bible aujourd'hui14. Quando fala de 'alfabetização bíblica' na verdade se refere ao uso do texto bíblico em vista do ensino das letras, como declara o Dr. Julian Sundersingh, coordenador mundial para a alfabetização, das Sociedades Bíblicas Unidas:

Des histoires bibliques sont utilisées dans le cadre du programme d'enseignement et, à la fin de leur formation, lês étudiants reçoivent généralement une bible ou un nouveau testament pour pouvoir poursuivre leur découverte des Ecritures et la transformation de leur vie (p. 6, 2018).

Observamos ainda a utilização do conceito de alfabetização bíblica ligado a renovação e aprofundamento do compromisso espiritual com a fé (SCHÉRER, 2018). Utiliza-se o método do Apóstolo Paulo em sua atividade missionário, que "compris les philosophies en vogue aussi bien que les idées répandues parmi les hommes du peuple" (WILLIAMS III, p.105, 2015). Porém nesses casos não se aprofunda o conceito de 'alfabetização bíblica' ou a didática a ser utilizada para atingir esse objetivo.

No âmbito Católico, destacamos a edição francesa do Bulletin Dei Verbum", do ano de 2014, sob o título "A Bíblia como 'código cultural"'. Nessa edição, o artigo "Le périple de Dei Verbum.

14. Para acesso a essa edição, do terceiro trimestre de 2011, segue o link: https://www. la-bible.ch/fileadmin/user upload/PDF/Services/Download/BA-f/BAf 11 3.pdf

15. Boletim Dei Verbum é publicado pelo Secretariado Geral da Federação Bíblica Católica. Como um fórum de reflexão sobre as questões do ministério pastoral bíblico, o Boletim Dei Verbum publica contribuições acadêmicas, relatórios sobre projetos e experiências de organizações membros individuais e sub-regiões da FBC, informa sobre as notícias da Federação e fornece informações sobre publicações recentes na área. Aparece duas vezes por ano em inglês, francês, alemão e espanhol. 
Impacts et défis", de Thomas Manjaly ${ }^{16}$, ao falar dos avanços colocados pelo documento conciliar, apresentou várias estratégias utilizadas em sua Diocese, na Índia, em vista de cumprir o mandato do Vaticano II, de "tornar acessível Sagradas Escrituras a todos os fiéis" (DV 22). Entre as ações e estratégias apresentadas pelo autor, destacam-se: Traduções da Bíblia, inclusive inter-religiosas; produção de materiais bíblicos; divulgação da Bíblia em meios eletrônicos; celebrações da Palavra (mesmo ecumênicas); formações diocesanas e paroquiais para lideranças; renovação litúrgica, como a prática da Liturgia das Horas; e, de um modo geral, a presença mais constante da Bíblia na vida da Igreja e das famílias (2014, p.42). Os frutos de tal ação, segundo Thomas Manjaly, foram, além de uma "meilleure conscience de la nécessité et de l'importance de la Parole de Dieu dans la vie de l'Église. [...] L'intérêt croissant chez les laïcs pour une lecture personnelle de la Bible" (MANJALY, 2014, p.42). De modo imediato, as ações relatadas_proporcionaram "le développement d'une 'culture biblique' ou d'une 'alphabétisation biblique"' (MANJALY, 2014, p.42). Por sua vez, ao falar dos desafios, dentre tantos, indica a necessidade de "promouvoir l'herméneutique contextuelle [...], qui suppose de lire la Bible en partant du point de vue des peuples" (MANJALY, 2014, p.45), e nesse momento convida a Igreja, os teólogos e demais estudiosos a darem sua contribuição na elaboração de novos métodos hermenêuticos - justamente o que nos motiva.

Mas, o texto que mais nos chamou atenção foi o de Yonat Shimron ${ }^{17}$, que em seu artigo "L'Ancien Testament est-il une lan-

16. Thomas Manjaly é professor de Sagrada Escritura a 30 anos em Shillong (Índia). É, desde de 2009, membro da Pontifícia Comissão Bíblica. tmanjalyotc@gmail.com.

17. Yonat Shimron é jornalista que escreve para o Jornal suiço Réformés (https://www. reformes.ch/). 
gue morte?" nos apresentou as reflexões do Professor Dr. Brent Strawn ${ }^{18}$, que não apenas compara o 'Antigo Testamento' a uma língua, como também sugere que estaria em vias de morrer (agonizando). No livro "The Old Testament is dying" o Professor Brent Strawn constatou a ausência de 'letramento bíblico' em muitos adultos, que desconheciam que as palavras proferidas na cruz, por Jesus, vinham do Salmo 22(23). Constatou também a aceitação de pessoas crentes e até seminaristas que Deus do Antigo Testamento é Deus da cólera, enquanto no Novo Testamento é o Deus de amor (SHIMRON, 2018). Citando o Professor Dr. Marcus J. Borg ${ }^{19}$, em seu artigo “'Speaking Christian': A Word of Introduction”, afirma haver uma crise de linguagem na religião, o que causaria uma crise na própria fé, "Because language is the medium through which people participate in the religion. To be part of a religion means being able to speak and understand its language" (BORG, 2011, apud. STRAWN, s/p, 2017).

Para o professor Strawn, tal negligência e/ou ignorância bíblica teria suas origens na pouquíssima leitura dos textos do Antigo Testamento mesmo nas Igrejas, bem como baixíssima utilização desses textos pelos líderes religiosos em seus sermões, sendo ambos os momentos importantes espaços de letramento ou 'alfabetização bíblica':

These individuals - or in some cases, groups of individuals (even entire churches) - do not regard the Old Testament in the some way (or as highly) as the New Testament, do not understand the Old Testament, would prefer to do without the Old Testament, and for all prac-

18. Brent A. Strawn é professor de Antigo Testamento e Diretor do Programa de Doutorado em Ministério na Escola de Teologia de Candler, Universidade de Emory. É, também, autor de vários livros.

19. Marcus J. Borg é professor emérito de 'Religião e Cultura' da Oregon State University, além de autor de vários livros sobre religião. É membro da 'Igreja Episcopal'. 
tical purposes do exactly that by means of their neglect and ignorance of it.

[...] The sad fact of the matter, however, is that most pastors seem less and less fluent in the language. This is no doubt due to a host of reasons that cannot by fully engaged or analyzed here. Here it suffices to make the point that, if religious leaders speak only a pidgin and pass only pidgin along to their flock, it is not hard to extrapolate from such a scenario to the predicament we face presently. On the one hand, many Christians don't seem to have the foggiest idea of what's in their Bibles in the first place and are therefore completely incapacitated when it comes to responding to substantive critiques from the New Atheism (or elsewhere) (STRAWN, 2017).

Sugerindo que justamente essa inabilidade com a língua bíblica, o iletrismo bíblico, estaria relacionado com o aumento de cristãos não praticantes e mesmo ateus, ao que poderíamos complementar, o aumento de cristãos avessos aos avanços científicos e fundamentalistas (não abertos a um diálogo crítico sobre a fé).

Ao final Strawn afirma que tal constatação demonstra que não basta ter feito seminário ou possuir um diploma para fazer uma pessoa "fluente" na língua bíblica, usando nossa terminologia, para fazê-lo "letrado biblicamente". É a constante leitura, estudo e prática que faz alguém "bilíngue" e, por consequência, aberto às riquezas da língua, no nosso caso, um verdadeiro "letrado bíblico": "So, while education can help set pastors on the right path, it is up to them to keep walking it - and not just through continuing-education units (though those don't hurt), but by constant immersion and practice" (STRAWN, s/p, 2017). E ao apresentar, seja um modelo de estudioso, seja de 'professor' dessa língua, cita Santo Agostinho, que como estudioso sempre assumiu uma posição crítica, não se contentando com o pouco, com o simples; e que como 'professor', destacou-se por sua capacidade de adaptar a linguagem bíblica a seus ouvintes (tivessem sido eles necessitados de 
uma formação básica; de uma formação para corrigir informações erradas; ou de uma formação mais crítica, em vista de aprofundar suas habilidades).

Para uma última pesquisa, tendo biblical literacy por palavra-chave, grande foi o número de sites, livros e artigos encontrados, muitos dos quais ao falar de "alfabetização bíblica" referem-se ao ensino dos conteúdos da Bíblia nas escolas, e um ensino, na grande maioria das vezes, voltado à memorização de datas, lugares, personagens e fatos descritos nos textos bíblicos. Foi possível, inclusive, encontrar um livro que trouxe dados estatísticos sobre tal prática ${ }^{20}$.

Em alguns dos casos, como no artigo "What is 'Biblical Literacy' and Why is it Important?", de Larry Perkins, do Northwest Center for Biblical and Theological Literacy, é apresentado como princípio norteador para uma 'alfabetização bíblica' a busca de um diálogo entre a cultura do passado (do texto) e do presente (do leitor), focalizando aspectos: linguísticos, semânticos, literários, além dos contextos histórico e social do texto e do leitor. Esses mesmos princípios coadunam-se perfeitamente àqueles assumidos por nós, em vista de um 'letramento bíblico'; pois a "Biblical literacy only attains its full potential when scriptural truth (i.e. wisdom) is applied for salvation and shalom individually and collectively [...]" (PERKINS, 2018), tendo por objetivo atender as necessidades do leitor e de seu amadurecimento na fé, criando um canal de diálogo entre o texto bíblico e ele, e não de mera e passiva recepção.

A apresentação sobre o que viria a ser "letramento" ou "alfabetização bíblica”, na verdade se resume a uma exposição acerca

20. Referimo-nos à obra: "Bible Literacy Report: What Do American Teens Need to Know and what Do They know?", de Marie Wachlin e Byron R. Johnson 
dos princípios hermenêuticos e do que se pretende com tal método, sem, contanto, detalhar os passos de tal método - o que justamente pretendemos realizar.

Há, ainda, sites, como o: https://www.biblical-literacy.org/lessons/, que apresentam lições com o objetivo de proporcionar um "letramento" bíblico, lições bastante didáticas e sob várias plataformas (slide, pdf, áudio e vídeo). Todavia, o foco de tais lições não está na interação entre o 'texto' e o 'leitor', mas apenas no 'texto' e em seu 'contexto de produção', o que sob o nosso ponto de vista não poderia ser enquadrado como uma proposta de "letramento", já que exclui o leitor como parte, inclusive, do conteúdo das lições.

Destacamos, porém, o artigo “'Speaking Christian': A Word of Introduction", do Professor Marcus J. Borg, pois apresenta uma reflexão bem próxima daquela que buscamos empreender, reforçando um sentimento vivenciado por nós em nossa realidade eclesial. Ao constatar o iliteracy Christian ele aponta para a necessidade de mudanças no método de apropriação da linguagem da fé (que por antonomásia é a linguagem bíblica), sem a qual um cristão não pode se verdadeiramente cristão, assim se expressando:

But Christian illiteracy is only the first part of the crisis. Even more seriously, even for those who think they speak "Christian" fluently, the faith itself is often misunderstood and distorted by many to whom it is seemingly very familiar. They think they are speaking the language as it has always been understood, but what they mean by the words and concepts is so different from what these things have meant historically, that they would have trouble communicating with the very authors of the past they honor. [...]

Every religion originated in a particular culture and thus used the language of that culture, even if in ways that radically challenged it. If a religion survived over time, it became a cultural-linguistic tradition in its own right, with its own language, its basic vocabulary, sacred texts and 
stories, rituals and practices. [...]

Christian language is grounded in the Bible and postbiblical Christianity. It includes the words used, heard, sung, and prayed in worship, devotion, teaching, and community. To be Christian is to know, use, and be shaped by this language-to live one's life with God within the framework of this language. (BORG, 2018).

Uma fé desprovida do real conhecimento dos conceitos, das expressões, das figuras de linguagem, dos intertextos, dos gêneros literários e dos símbolos empregados nela, se tornaria, na verdade, apenas um repetidor do que fora dito por outros a ele; a nível linguístico, se manteria preso à literalidade dos textos bíblicos, o que chamamos de "leitura parafrástica", a qual buscamos superar.

\section{Contribuição da teoria do letramento ao ensino bíblico}

Um método de letramento bíblico busca promover um contato com as Escrituras que permita o leitor interpretar o texto a partir de seus conhecimentos, daquilo que ele já sabe, e não do que ele desconhece. Este processo é mais próximo daquele utilizado pelo próprio Jesus para transmitir os conhecimentos sobre o Pai e seu Reino. É um método acoIhedor, inclusivo, promove uma "verdadeira espiritualidade encarnada na cultura dos simples. Assim recordou o Papa Francisco (EG 124) inspirado na boa nova revelada aos pequeninos (Mt 11,26).

Julgamos que o letramento aplicado ao ensino bíblico pode ser instrumento eficaz para alcançar os objetivos da leitura bíblica no contexto eclesial, sobretudo aliado ao método da leitura popular nos Grupos Bíblicos de Reflexão. Recordamos aqui as orientações e exortações de documentos da Igreja em relação a importância e necessidade de promover um encontro dos fiéis com a Bíblia, enquanto Palavra de Deus.

A Igreja do Brasil, no documento "Discípulos e Servidores da Palavra de Deus na Missão da Igreja" (Doc 97, n.8-7.17.29-31), promove um resgate do caminho já percorrido pela 'Pastoral Bíblica'. Salienta a força 
que a 'Pastoral Bíblica' ganhou na Igreja após o Concílio Vaticano II, fazendo com que a Palavra de Deus fosse conhecida, rezada, vivida e anunciada. Louva a apresentação do conceito de Revelação sob uma perspectiva de diálogo, um diálogo entre Deus e os homens, requerendo deste uma postura de abertura e acolhimento. Por necessidade a Revelação passa a ser compreendida como um evento comunicativo de Deus em diálogo conosco por amor, e convida-nos, continuamente, a entrar em comunhão com Ele (DV 6). Destaca Bento XVI, que isso acontece porque nossa fé não é crer numa palavra escrita e muda, pois é a fé no Verbo Encarnado e vivo (VD 7).

Desse modo, entendida como encontro, a Palavra, não só requer que Deus fale e o homem responda, mas que Ela continue mantendo-se sempre presente/ viva/ eficaz, como nos prometeu o Senhor: "Eis que estarei convosco todos os dias, até o fim do mundo" Mt 28,20 (VD 51; Doc 97, n.24). É importante destacar que esse encontro é um caminho que leva não só a conhecer a Deus, mas também a compreender a si mesmo e ao mundo, sendo isto algo que se dá pela leitura, escuta e interpretação na e com a Comunidade (Doc 97, n.38-39). Nesta perspectiva a Exortação Apostólica Verbum Domini (VD 53) e o Documento 97 da CNBB (n.10) apresentam as três dimensões da Bíblia como Palavra de Deus, dimensões que devem ser levadas em conta para sua plena compreensão: Dimensão Comunicativa= Deus se dá a conhecer; Dimensão Dialógica = a revelação se dá como encontro; Dimensão Performática= esse encontro é significativo e transformador.

Consciente do percurso que a Igreja vem fazendo e do apelo inerente à própria Palavra de Deus, de um Deus que vai ao encontro de seu povo, a Igreja busca interpretar as Escrituras que leve a experiência com Cristo tal como aconteceu no caminho de Emaús (Lc 24,13-34). Há várias décadas na Igreja do Brasil as CEBs figuram como instrumentos da ação divina e eclesial para que a Palavra de Deus pudesse ser cada dia mais conhecida nas comunidades e promovesse uma transformação 
da realidade ${ }^{21}$. E desde seu surgimento, as CEBs "[...] têm demonstrado grande riqueza e criatividade em sua maneira de ser e viver a vocação de Igreja presente no mundo" (Doc 25, n.31), pois têm na Palavra e na Eucaristia o seu centro e alimento (Doc 100, n.230; Doc 25, n.32).

Essa centralidade da Palavra é tão forte nas CEBs que em algumas Dioceses são chamadas de Grupos Bíblicos de Reflexão. Por meio desses grupos a Igreja assume seu dever de ensinar em termos simples e práticos, dimensões de sentido do texto bíblico, sem requerer dos leitores conhecimentos sócio-históricos ou literários mais especializados ${ }^{22}$. Essas práticas de leitura promovem mais que o estudo do texto, uma mudança de vidas. Na caminhada cristã, mais que doutores, se requer dos cristãos que sejam santos (Doc 97, n.47).

No entanto para se ter acesso ao texto como Palavra de Deus é importante que o leitor de fé seja capaz de compreender todo o potencial de sentido presente na literalidade do texto, preservando de aproximações fundamentalistas ${ }^{23}$ ou ideológicas ${ }^{24}$ (Doc 97, n.42). É por este motivo que a Verbum Domini (VD 75), na esteira dos documentos Conciliares, e a Igreja do Brasil (Doc 97, n.74.79-80), incentiva estudos aprofundados de exegese bíblica, que sejam elaborados materiais que subsidiem a formação dos fiéis. Com isso a Boa Nova pode chegar a um maior número. Quando o texto bíblico é lido com atenção no estudo, aliado a fé iniciam-se processos de conversão pessoal, comunitária e pastoral de modo a tornar as pessoas testemunhas corajosas (Doc 97, n.60). Pois bem, para aprimorar no povo a consciência do valor da Bíblia pela qual Deus fala

21. As ideias-chave que nutrem as CEBs são (Doc 25, n.12): A Igreja como Povo de Deus conduzido pelo Espírito; a Igreja como sacramento da unidade entre o homem e Deus, e dos homens entre si, em outras palavras, a Igreja como Comunhão (LG 1); o papel insubstituível do leigo na Igreja (LG 76); e a Igreja entendida como fermento (LG 32).

22. É justamente esta postura de ensino das Escrituras que o Documento "A Interpretação da Bíblia na Igreja", da Pontifícia Comissão Bíblica, destaca como sendo o mais frutuoso para os fiéis (1993, p.57).

23. Nessa perspectiva, o fundamentalista é aquele que identifica a Escritura com a Palavra de Deus (Doc 97, n.43).

24. Os que agem sob ideologias seriam aqueles que impõem um sentido estranho e/ou subjetivo às Escrituras (Doc 97, n.44). 
a humanidade, se requer abertura a novos métodos. Percebe-se nos documentos da Igreja o interesse aprimorar o método de interpretação mediante o diálogo com outros métodos.

A afirmação bakhitiniana de que a linguagem, quando usada por alguém, vem marcada pelas influências, pelos pressupostos de seu enunciador (BAKHTIN, 1997, p.58.107), portanto, nunca é neutra (BRITTO, 2003, p.59). Isso se aplica quando o objeto de análise são os textos bíblicos. Com efeito o leitor se envolve na dinâmica e mensagem do relato. $\mathrm{O}$ estudioso norte-americano Brian Singer-Towns declara que "the christian bible has a specific and intentional structure. once a person understands this structure, navigating through for the Bible becomes much easier. Unfortunately, many people are unaware of this" (2008, p.16). Tal declaração se dá no contexto de incentivo ao 'letramento bíblico' dos fiéis, em resposta ao pedido do Concílio Vaticano II, de que os fiéis tenham livre acesso à Sagrada Escritura (DV 22). O letramento bíblico conduz o fiel a compreender o conteúdo na unidade da Escritura, indo além de uma leitura parafrástica. A leitura também envolve existencialmente o leitor. Aqui se entende a intensão do concílio manter um contato íntimo com as Escrituras (DV 25).

O Literalismo (a leitura 'parafrástica') é justamente um dos pontos que a Verbum Domini propõe que seja superado e evitado pela Igreja, pois os que assim se relacionam com as Escrituras evitam a íntima ligação que existe entre o divino e o humano, quando pensamos nas ações de Deus (VD 44). O Papa Bento XVI recorda que o autêntico processo interpretativo nunca se resume à dimensão intelectual e à mera literalidade do texto. É sempre "preciso transcender a letra" para atingir a Palavra do próprio Deus, num processo pelo qual se deve deixar guiar pelo "movimento interior do conjunto", tornando-se também "um processo de vida" (VD 38). Esta busca fiel de interpretar nos torna capazes de fugir de abordagens individualistas, já que o objetivo da Palavra é a Comunhão (VD 86). 
Entretanto, para que isso aconteça é necessário que os fiéis se tornem capazes de identificar os diversos significados e compreender o sentido unitário da Palavra de Deus na sinfonia da diversidade de vozes que a compõe (VD 7; Doc 97, n.13-15). A leitura atenta das Escrituras conduz o leitor a descobrir sua riqueza e reserva de sentido, uma Boa Nova. Com efeito "a Escritura não pertence ao passado e seu sujeito interpretante é o povo de Deus inspirado pelo próprio Deus e seu Espírito (VD 86).

Quando comparada a outros métodos de análise como a semiótica, narrativa e retórica é possível identificar pontos comuns entre eles e a proposta que apresentamos. Destacamos alguns: $1^{\circ}$ ) Assim como a análise semiótica o método de letramento bíblico parte do pressuposto de que existem elementos na estrutura redacional dos enunciados que contribuem para sua compreensão, como um todo portador de sentido. Esses elementos assumem a perspectiva de que só existe enunciação quando há diálogo. O diálogo é mediado pela linguagem em uso; 2) $\mathrm{Na}$ análise narrativa temos o narrador e o leitor,. No letramento existe um enunciador que colabora com o enunciado,além de ver cada gênero textual como portador de um número limitado de sentidos próprios a seu objetivo, relativamente estável quanto a seu tema, composição e estilo (PONTIFÍCIA COMISSÃO BÍBLICA, 1993, p.54-55; BAKHTIN, 1997, p.285.332.352-353; BAKHTIN, 2006, p.99). $2^{\circ}$ ) Tal como afirma a análise narrativa, para o método do letramento bíblico sempre existe um enunciador que elabora seu enunciado tendo em vista um enunciatário; e para que seja possível entender um enunciado é importantíssimo compreender seu contexto de produção e de divulgação (PONTIFíCIA COMISSÃO BÍBLICA, 1993, p.51-53; BAKHTIN, 1997, p.35). 3) Tanto a análise retórica quanto o método do letramento bíblico se preocupam em compreender como a linguagem é usada para promover determinado efeito de sentido (PONTIFÍCIA COMISSÃO BÍBLICA, 1993, p.49-50; BAKHTIN, 1997, p.332).

Há, todavia, uma especial proximidade entre o método de Letramento 
Bíblico com aquele elaborado pelo Frei Carlos Mesters - da Leitura Popular da Bíblia. Ambos os métodos têm como característica a valorização da história individual daquela pessoa ou grupo que se aproxima do enunciado bíblico, promovendo um frutuoso diálogo entre Deus e seu povo. Uma intimidade com os enunciados, as estruturas e os gêneros, seu contexto de produção e divulgação, que busca fazer com que sua compreensão vá se aprofundando e a enunciação que estava enublecida vá se tornando clara e distinta, já não restrita a um grupo seleto (MESTERS; OROFINO, 2017). Porém, na tríade - Texto; Contexto e Leitor - apresentada pela Leitura Popular da Bíblia, essa relação dialógica promove uma 'ampliação conceitual' do texto bíblico, que vai sendo desnudado em suas sutilezas e a unidade da mensagem vai sendo percebida, podendo ser assumida de modo mais consciente. No caso do método do Letramento, o objetivo recai na 'ampliação conceitual' do leitor, que no diálogo com o texto coloca a si e sua vida como ponto de partida, e deste modo vai percebendo respostas de Deus para seus conflitos, fazendo que o leitor veja a si e o texto, a cada novo diálogo, sob uma nova perspectiva.

\section{Considerações finais}

A discussão em torno das 'Teorias de Letramento aplicadas ao ensino bíblico' é bastante recente no meio acadêmico, como no contexto eclesial, seja no Brasil seja em países como França, Itália e Estados Unidos. Constata-se muitos conteúdos de caráter literalista ou voltados a uma perspectiva de leitura tradicional, apresentados por alguns autores como 'letramento bíblico'. O letramento bíblico aplicado ao ensino conduz ao sentido mais pleno do texto. Novos métodos ligados às ciências da linguagem surgiram. No contexto eclesial a teoria do letramento associada a leitura popular pode tornar o texto mais acessível aos leitores, na sua riqueza de significados. O desafio de superar uma leitura perifrástica na prática foi enfrentado com as CEBS e a leitura popular, acentuando no seu método a ligação da Bíblia com a Vida. Porém longo caminho de 
aplicação de novos métodos precisa ser realizado.

No presente estudo mediante contato com pesquisas em outras línguas foi possível identificar mais claramente os anseios da Igreja pela estruturação de um método acessível as pessoas mais simples. Essa forma de apropriar-se do texto da Bíblia ligado com a situação existencial visa levá-los não a um conhecimento científico acerca das Escrituras, mas um conhecimento transformador, capaz de enriquecê-los espiritualmente e desse modo agir diretamente sobre suas práticas.

As Teorias de Letramento se mostraram em perfeita sintonia com os anseios da Igreja e com a busca da Teologia, em nossos dias. A compreensão da leitura como articulação entre autor, texto, leitor, contexto, e a identificação do intertexto indicam o rumo para uma leitura polissêmica. O texto não é letra morta do passado. Enquanto lido, em contato com o leitor como sujeito interpretante, o entendimento do texto conduz a um conhecimento que se torna transformador pois incide na práxis cristã.

Espera-se que os conhecimentos advindos das Teorias de Letramento possam cooperar com os métodos já utilizados pela Igreja do Brasil - como o método elaborado pelo Frei Carlos Mesters -, superando o que alguns teóricos chamam de "analfabetismo bíblico" de muitos fiéis. Espera-se com esse método, a partir da superação de uma leitura 'parafrástica', encaminhar o leitor/fiel a uma leitura 'polissêmica' dos textos bíblicos, ampliando a compreensão dos diferentes níveis enunciativos presentes em cada um dos diferentes gêneros bíblicos. Aderindo mais conscientemente à mensagem/enunciação neles contidos, vendo-os como 'vida'/'texto vivo' e não como 'letra morta'. Assim, a aplicação do método ajudará o leitor fiel ler as Sagradas Escrituras com uma compreensão mais ampla e como mensagem de Deus.

\section{Referências}

BAKHTIN, M. Estética da Criação. São Paulo: WMF, 1997.

BAKHTIN, M. Marxismo e filosofia da linguagem. 12. ed. São Paulo: HUCITEC, 
2006.

BARGHILIONI, M.; BARGHILIONI, E.; MEDDI, L. Adulti nella comunità Cristiana: Guida alla preparazione di itinerari per l'evangelizzazione, la crescita nella fede e la mistagogia della vita Cristiana. Paoline: Milano, 2008

BENTO XVI. Exortação Apostólica Verbum Domini. São Paulo: Paulinas, 2010.

Bíblia de Jerusalém. 10. ed. São Paulo: Paulus, 2015

Bíblia Sagrada. 2. ed. São Paulo: CNBB, 2002.

BORG, M. J. "Speaking Christian": A Word of Introduction. Disponível em: <http://day1.org/2896-dr marcus i borg speaking christian a word of introduction>. Acesso em: 10 jun. 2018.

BRITTO, L. P. L. Língua e Ideologia: a reprodução do preconceito. In: BRITTO, L. P. L. Contra o consenso: cultura escrita, educação e participação. Campinas: Mercado de Letras, 2003.

$B R O N C K A R T$, J. P. Atividade de linguagem, texto e discurso: por um interacionismo sociodiscursivo. São Paulo: Educ, 2009.

CONGREGAÇÃO PARA A DOUTRINA DA FÉ. Instrução Donum Veritatis. 2. ed. São Paulo: Paulinas, 1999.

COMISSÃO TEOLÓGICA INTERNACIONAL. Teologia Hoje, perspectivas, princípios e critérios. São Paulo: Paulinas, 2013

COMPÊNDIO do Concílio Vaticano II. São Paulo: Vozes, 2002.

CONFERÊNCIA NACIONALDOS BISPOS DO BRASIL. Comunidade de Comunidades: uma nova paróquia. São Paulo: Paulinas, 2014.

CONFERÊNCIA NACIONAL DOS BISPOS DO BRASIL. Comunidades Eclesiais de Base na Igreja do Brasil. 6. ed. São Paulo: Paulinas, 1999.

CONFERÊNCIA NACIONAL DOS BISPOS DO BRASIL. Discípulos e Servidores da Palavra de Deus na Missão da Igreja. São Paulo: Paulinas, 2012.

CONGREGAÇÃO PARA A DOUTRINA DA FÉ. Instrução Donum Veritatis. Disponível em: <http://www.vatican.va/roman curia/congregations/cfaith/documents/rc con cfaith doc 19900524 theologian-vocation po.html >. Acesso em: 30 abr. 2018.

COSSON, R. Círculo de leitura e letramento literário. São Paulo: Contexto, 2014. FRANCISCO. Exortação Apostólica Evangelii Gaudium. São Paulo: Paulinas, 2013. FREIRE, P. A importância do ato de ler: em três artigos que se completam. São Paulo: Cortez: Autores Associados, 1992.

JOÃO PAULO II. Exortação Apostólica Christifideles Laici. 11. ed. São Paulo: Paulinas, 2013. 
KLEIMAN, Â. B. Modelos de letramento e as práticas de alfabetização na escola. In: KLEIMAN, Â B. (Org.). Os significados do letramento: uma nova perspectiva sobre a prática social da escrita. Campinas: Mercado das Letras, 2008.

MANJALY, T. Le périple de Dei Verbum. Impacts et défis. Bulletin Dei Verbum, n. 98, 2014: 34-49.

MASELLI, D. L'alfabetizzazione della Bibbia. Disponível em: <http://bes.biblia. org/riflessioni/lalfabetizzazione-della-bibbia.html?showall=1\&limitstart>. Acesso em: 01 maio 2018.

MESTERS, C.; OROFINO, F. Sobre a Leitura Popular da Bíblia - parte I. Disponível em: $\quad<$ https://www.cebi.org.br/2007/10/14/sobre-leitura-popular-da-biblia-parte-i/>. Acesso em: 20 out. 2017.

PERKINS. L. What is "Biblical Literacy" and Why is it Important? Disponível em: $<$ http://biblicalliteracy.nbseminary.ca/what-is-biblical-literacy-andwhy-is-it-important/>. Acesso em: 09 jun. 2018.

PINSKY, J. As Primeiras Civilizações. 15. ed. São Paulo: Contexto, 2011

Pontifícia Comissão Bíblica. A Interpretação da Bíblia na Igreja. São Paulo: Paulinas, 1993.

REX, L.; GREEN, J.; DIXON, C. Critical Issues: What Counts When Context Counts?: The Uncommon "Common" Language of Literacy Research. Journal of Literacy Research, vol. 30, n. 3, 1998: 405-433.

SCHÉRER, M. Quels sont les devoirs d'un ministre de l'Éducation? Disponível em: <http://parletion.com/article/quels-sont-les-devoirs-d-un-ministre-de-l-education>. Acesso em: 06 jun. 2018.

SHIMRON, Y. L'Ancien Testament est-il une langue morte? Disponível em: $<$ https:// www.reformes.ch/culture/2017/08/lancien-testament-est-il-une-langue-morte-bible-ancien-testament-codex-langue-morte>. Acesso em: 06 jun. 2018.

SINGER-TOWNS, B. Biblical Literacy Made Easy: A Practical Guide for Catechists, Teachers, and Youth Ministers. Winona: Saint Mary's press, 2008.

SOARES, M. Letramento: um tema em três gêneros. 3. ed. Belo Horizonte: Autêntica, 2009.

SOCIEDADES BÍBLICAS UNIDAS. ¿Alfabetization Biblica: conoces la Palabra de Dios? Disponível em: <http://impactoevangelistico.net/noticia/6836-alfabetizacion-biblica-conoces-palabra-dios>. Acesso em: 05 maio 2018.

STRAWN, B. A. The Old Testament is dying. Grand Rapids: Baker Academic, 2017.

SUNDERSINGH, J. A l'échelle mondiale. In: SOCIÉTÉ BIBLIQUE SUISSE. La Bible 
aujourd'hui. Disponível em: <https://www.la-bible.ch/fileadmin/user upload/PDF/Services/Download/BA-f/BAf 11 3.pdf>. Acesso em: 01 jun. 2018.

WILLIAMS III, H. H. D. Trois influences dans la formation de Paul, l'apôtre missionnaire. Journal du Christianisme Mondial, vol. 1, n. 1, 2015: 100105. 